\title{
ENGENHEIRA \& GERENTE: DESAFIOS ENFRENTADOS POR MULHERES EM POSIÇÕES DE COMANDO NA ÁREA TECNOLÓGICA
}

Engineer and manager: challenges to women in managerial positions in technological areas

Maria Rosa Lombardi*

\section{Resumo}

Baseando-se em entrevistas com engenheiras que desempenharam, em algum momento de suas trajetórias profissionais, funções de alta gerência ou diretoria, o artigo discute alguns dos obstáculos encontrados por essas profissionais no seu processo de inserção e progressão naqueles postos de comando. Identifica, ainda, alguns diferenciais de gênero a que estiveram sujeitas aquelas engenheiras nesse percurso, a começar pela maior dificuldade em assumir essas funções. Ainda, algumas delas tiveram que ser suficientemente criativas e hábeis para lidar com situações de conflito explícito com os engenheiros subordinados, a fim de permanecer no comando da equipe masculina.

Palavras-chave: Mulheres em postos de comando; engenheiras; carreiras femininas na área tecnológica.

\section{Abstract}

Based on interviews with female engineers who at some point of their careers worked in leading management positions, this article discusses some of the difficulties found by these professionals in reaching and making progress trough these managerial positions. The study identifies some gender related difficulties they faced in entering the management career and the creative

* Mestre e doutora em Educação, área Ciências Sociais Aplicadas à Educação, pela Faculdade de Educação da UNICAMP- Universidade Estadual de Campinas. Pesquisadora na Fundação Carlos Chagas, São Paulo. (mlombard@fcc.org.br) 
and skilled ways they found to deal with conflict situations with subordinate engineers, in order to remain in control of male working teams.

Keywords: women in chief management positions; female engineers; women careers in technological area.

\section{INTRODUÇÃO}

A maior presença de mulheres engenheiras hoje, comparativamente há trinta e cinco anos atrás, tem alterado os contornos da divisão sexual do trabalho na Engenharia brasileira, na direção do aumento da participação feminina em um maior número de especialidades, áreas de trabalho e atividades profissionais. No entanto, diversos estudos indicam a persistência de várias ordens de impedimentos ao maior ingresso das mulheres na profissão, bem como à sua progressão nas carreiras. Uma das razões, sempre invocadas quando se trata de procurar entender o limitado interesse das mulheres pela Engenharia, remete às suas origens militares, ao exercício de funções de comando, às duras condições de trabalho (Wajcman, 1996; Terra da Silva, 1992; Silva Telles, 1984; Marry, 2002). Outra, lembra que o maior poder de abstração (e matemática e a física) é associado ao masculino, enquanto a química evocaria o gosto pela experimentação e pelo concreto, associado ao feminino e às qualidades da paciência, observação e intuição, remetendo a questão à esfera das representações sociais e de gênero das disciplinas e das especialidades da engenharia (Marry, 2002). Outra ainda, identificará como razões da exclusão, conflitos e dificuldades de adaptação das mulheres em culturas profissionais masculinas (Faulkner, 2005). No nosso ponto de vista, não menos desprezível para manter a sub-representação das mulheres na Engenharia é a existência de discriminação de gênero nos ambientes de trabalho, que se manifesta de variadas formas. No exercício profissional, por exemplo, na medida em que se atribuem às mulheres determinadas áreas de trabalho e certas atividades profissionais, em detrimento de outras. Mas talvez, uma das maiores barreiras encontradas pelas engenheiras em suas carreiras seja ascender a postos de comando nas organizações. Essa limitação ascensional, é verdade, se verifica para as trabalhadoras, de uma forma geral. 
Mesmo que as mulheres venham assumindo cargos de responsabilidade na gerência e na diretoria das empresas, é rara sua presença no topo da hierarquia empresarial, processo designado "teto de vidro" (Laufer e Fouquet, 1997; Bruschini, 2004). Parte desses obstáculos se inscreve na própria condição feminina, como é entendida e vivida na nossa sociedade, que atribui à mulher a quase integral responsabilidade pelo cuidado da família e dos filhos. Outros obstáculos provêm da própria empresa e dos comportamentos esperados por parte de quem pretende ascender na hierarquia, qual seja, seguir o modelo masculino de disponibilidade de tempo e dedicação exclusiva à carreira. Outro impedimento residiria numa certa resistência feminina para enfrentar a competição profissional e para assumir o desafio da direção de equipes.

$\mathrm{O}$ artigo pretende discutir essas questões, analisando-as sob o ponto de vista das relações sociais de sexo, ou relações de gênero. Para tanto, recorreu-se às vivências de engenheiras e engenheiros que desempenharam, em algum momento de suas trajetórias profissionais, funções de alta gerência ou diretoria ${ }^{1}$ e, a partir delas, pretende-se iluminar alguns diferenciais de gênero identificados no processo de inserção e progressão dos(as) profissionais, naquelas posições hierárquicas.

1 A pesquisa em questão, no Brasil e na França, entre 2003/2004. Foram realizadas 33 entrevistas pessoais com engenheiros (7) e engenheiras (26), alguns deles também sindicalistas e um, diretor de escola de engenharia. Na fase exploratória da pesquisa de campo, tivemos a oportunidade de realizar 8 entrevistas com engenheiras e sindicalistas francesas indicadas por diversas instituições, por ocasião de um estágio de doutorado. Essas entrevistas se deram a partir de indicações de diversas instituições, sem controle a priori de variáveis como sexo, idade, especialidade, situação profissional em que se encontrava no momento da entrevista. Objetivaram, basicamente, ouvir as engenheiras sobre suas carreiras, a profissão e suas mudanças recentes e testar roteiro de entrevista preliminar. Os resultados da fase exploratória foram bastante satisfatórios, ultrapassando esses objetivos inicialmente propostos. A partir da análise dos depoimentos recolhidos na França identificaram-se processos e padrões de relações de gênero no campo de trabalho da engenharia, os quais se repetiram e foram reafirmados pelos relatos dos entrevistados brasileiros de ambos os sexos, legitimando a inclusão das entrevistas da fase exploratória na amostra final. Como esclarecem Beaud e Weber (2003), se ao realizar entrevistas em profundidade não se pretende generalizar os achados para outras populações, a generalização é desejável e possível quando se abordam processos e relações, exatamente a intenção central deste estudo, qual seja, as relações de gênero na engenharia e sua evolução nas últimas três décadas. A pesquisa de campo no Brasil tomou como âmbito geográfico principal a Região Metropolitana de São Paulo; a amostra da pesquisa foi composta por 


\section{GERÊNCIA NO FEMININO E NO MASCULINO: DIFERENCIAIS DE GÊNERO E DIFICULDADES ENCONTRADAS}

A grande maioria dos (as) engenheiros(as) entrevistados(as) assumiram algum cargo de comando em suas trajetórias profissionais, desde, no mínimo, “responsável” por um serviço ou área, até diretor, superintendente.

Mesmo que o número de engenheiros do sexo masculino entrevistados tenha sido pequeno (sete em trinta e três entrevistados), de uma forma geral, nos relatos dos homens praticamente não houve menções a eventuais barreiras ou dificuldades para ascender a postos de comando, passando a impressão de que esse percurso era esperado por eles e por seus empregadores, portanto, correu "normal". Como afirma Fortino (2002), o padrão de ascensão masculino, diferentemente do feminino, tende a se dar de forma linear, com os profissionais escalando paulatinamente sucessivos postos na hierarquia. Esse processo costuma acontecer por cooptação; seus pares os convidam para assumir sucessivos postos de comando, trajetória considerada "natural" para um homem.

De fato, três dos engenheiros entrevistados, Lauro, engenheiro civil (56 anos), Francisco, engenheiro mecânico e sindicalista (45 anos) e Marcos, engenheiro de produção (46 anos), explicitaram a presença dos seus pares na sua trajetória profissional, convidando-os a se integrarem a grupos de especialistas ou a assumirem cargos de responsabilidade em empresas.

Marcos, atualmente diretor-geral de empresa multinacional da área de softwares de logística, conta com naturalidade como, no decorrer de

indicações que partiram dos próprios entrevistados, iniciando-se o processo de "amostra intencional" a partir da primeira entrevista com uma engenheira. Na seleção da amostra procurou-se , dentro das possibilidades de uma amostra intencional, considerar os seguintes parâmetros: _a diversidade das especialidades da engenharia combinada à presença das mulheres nas especialidades, _o fator geracional ( entrevistando engenheiros (as) formados(as) na graduação, nos anos 1970, 1980, 1990 e 2000) e,_diferentes vínculos de trabalho. Quatro questões principais orientaram de forma geral a pesquisa qualitativa : 1)Ser uma mulher e ser um homem numa escola de engenharia é a mesma coisa? E na empresa? ; 2) Quais são os espaços de estudo e de trabalho atribuídos às mulheres na engenharia? E aos homens?; 3)É possível identificar mudanças no trabalho das engenheiras e dos engenheiros nas últimas décadas? Em caso positivo, quais as principais? 4) Como as engenheiras vivem subjetivamente a sua condição de mulheres numa profissão tradicionalmente masculina? Elas identificam situações ou processos de discriminação de gênero em suas trajetórias profissionais? 
sua carreira, foi se especializando e sendo reconhecido como um expert na sua área, foi sendo convidado para assumir posições de destaque em várias empresas.

"Aí recebi um convite e, em fins de 1993, minha vida mudou de novo; fui para a $W$, empresa de softwares de gestão empresarial, (produtos) parecidos com os da empresa em que trabalhei antes... me convidaram para cuidar da área comercial e me nomearam gerente da empresa no Brasil...... em 1999 fui convidado para ser gerente da empresa $Z$, multinacional de consultoria especializada em softwares... como o responsável geral do Brasil...em 2003 recebi um novo convite de outra multinacional de softwares de logística que até então estava atuando na América Latina só através de revendedores e queria impulsionar negócios. Me convidaram para ser o responsável dessa empresa na $A L$. "

Também Francisco se refere a convites de colegas que lhe permitiram dar seqüência à trajetória de especialista na área de transporte coletivo eletrificado, atuando em grandes empresas públicas e privadas, na montagem de equipes de trolebus:

“...fui chamado para trabalhar na empresa $M$, sou oriundo do grupo do trolebus, na época em que a gestão começou a trazer a engenharia de manutenção para dentro da empresa, que não existia... entrei em 1984 para formar a equipe de trolebus.... a gestão seguinte caçou todo o pessoal técnico.... mas um colega me convidou para montar a rede de trolebus que hoje é a EMTU-Empresa Metropolitana de Transportes Urbanos..."

Lauro, hoje consultor especializado em engenharia rodoviária, fala de sua progressão profissional em instituição rodoviária, de forma muito lacônica, mencionando de passagem que lá chegou a diretor da área de engenharia. Talvez, por lhe parecer absolutamente óbvia essa progressão. 
"Na época , o Brasil precisava de estradas, era a época do milagre econômico, e quando saí da escola (1971) surgiram uma porção de oportunidades de emprego e um amigo me chamou .... fui ser engenheiro auxiliar na construção da estrada Cuiabá a Campo Grande... fiquei lá um ano e meio, depois fui para Porto Velho para trabalhar num projeto, ... depois voltei para São Paulo porque minha família é daqui. Interessante como experiência profissional, cheguei a diretor, tudo"

Como também comenta Fortino (op.cit), de uma maneira geral, as carreiras femininas tendem a não ser lineares como as masculinas, apresentando longos períodos de estagnação e algumas arrancadas abruptas em direção a posições mais elevadas, sendo menos comum a menção da presença de um grupo de referência profissional, que lhes tenha convidado para integrá-lo como especialista ou para dirigir empresas. Em geral, nos seus relatos aparece a figura de uma pessoa excepcional, um homem que confiou nelas em um determinado momento da carreira e as indicou para um posto de comando na estrutura da empresa.

São em geral, eventos únicos e sem repetição nas suas carreiras. Embora também se trate de cooptação (e talvez por não ser comum nem contínuo), as mulheres tendem a encarar o processo de forma individualizada, como uma gentileza de um homem excepcional , especialmente dirigida a elas, pela qual serão sempre reconhecidas. Em sua ascensão hierárquica , porém, o que, certamente, há de recorrente é a necessidade permanente de prova das competências profissionais. E este é um diferencial de gênero, na medida em que os homens não precisam passar por essa prova constantemente.

No caso das entrevistadas, o padrão de ascensão hierárquica apresentou vários dos elementos citados pela autora mencionada. Como demonstram as histórias de Chantal e Rose, as engenheiras mais velhas da amostra, ambas com 55 anos, foi fundamental a presença de um homem, um profissional hierarquicamente superior que confiou nelas e thes deu chances de progredir. Além disso, outros fatores intervieram para tornar a ascensão das entrevistadas mulheres mais fácil ou mais difícil: o fator 
geracional, a sua área ou campo de trabalho, a recusa das empresas em aceitar suas demandas, o seu interesse por esses postos e as interfaces da carreira com a vida conjugal e familiar.

O caso de Isabelle, engenheira de produção francesa, de 45 anos, é um exemplo de estratégia empresarial que coloca obstáculos à ascensão hierárquica, não valorizando na medida devida, um trabalho de assistência técnica especializada ao cliente. A empresa em que trabalha, de porte médio, é uma multinacional francesa do ramo químico que fabrica luvas profissionais de borracha. Lá, Isabelle montou o serviço de assistência técnica ao cliente, pelo qual era responsável. Suas funções exigiam competências técnicas específicas para discutir sobre problemas de alergia com médicos, conhecimentos de química e de operações químicas, legislação de segurança, saber explicar noções técnicas do produto, formar pessoas, explicando o produto para distribuidores e vendedores, diretamente, no mundo todo, escrever artigos informativos em revistas especializadas, falar várias línguas, ser, enfim, "muito polivalente". Ela é muito reconhecida na área técnica na Europa e no mundo como expert em EPI - Equipamentos de Proteção Individual no trabalho e na sua empresa também. Mas, apesar de toda essa performance, que desenvolve praticamente sozinha, nas suas palavras, "sofro pelo não reconhecimento oficial do meu trabalho na empresa”, não conseguindo vê-lo suficientemente valorizado, a ponto de se transformar numa diretoria.

"Numa empresa como esta, há maiores perspectivas para uma mulher da área de finanças e marketing do que para uma mulher engenheira se tornar diretora. Quero transformar meu serviço numa diretoria, desagregá-lo do marketing, mas isso tem sido difícil. Acho que é porque sou mulher, pois os colegas homens em serviços similares em outras empresas já ascenderam a postos de diretoria. É frustrante porque todo o meu trabalho é considerado um "serviço" como outros, comercial, administrativo etc. $O$ que fazer? Tenho tentado estruturar o trabalho com um conjunto de funcionários, sobretudo técnicos, mas não tem dado certo" 
Chantal, engenheira de 55 anos, diretora de alto escalão do banco $\mathrm{F}$, um grande banco privado francês, no qual trabalha há trinta anos, mostrase bastante consciente dos limites que a organização impôs a sua ascensão, quando comparada a dos seus contemporâneos do sexo masculino. Da mesma forma, entende que isso se deve muito a uma questão geracional, pois como primeira mulher diretora nesse banco, enfrentou uma resistência maior do que as engenheiras enfrentam hoje em dia.

"Quando entrei na empresa já entrei numa posição de gerência e no banco $F$ há um sistema de promoção que vai da classe 5 a 8 e, em seguida, os níveis "fora de classificação", destinados aos gerentes e diretores de alto escalão. Eu galguei até a classe 8 onde me deixaram por 12 anos sem promoção. Recentemente obtive meu "bastão de marechal", significando que é o máximo que vou obter na hierarquia, dali será muito difícil passar. No ano passado fui reconhecida como "fora de classificação" e comecei a entrar na carreira dos gerentes de alto nível do banco, mas na base da escala dessa categoria e ainda não tive o aumento de salário correspondente. É uma promoção honorífica, não terei mais nada até a aposentadoria... Durante toda minha carreira solicitei várias vezes transferência para setores operacionais como, p.ex., gerência de agência e também pedi para trabalhar no exterior, mas tudo foi negado. Sobretudo quando pedi transferência para $o$ estrangeiro, me perguntaram: "e seu marido?", respondi "ele vem comigo, não tem problema", mas esse era um padrão muito diferente do aceito pelo banco para uma mulher... Acho que é uma luta de poder dos homens e, como há poucas mulheres que poderiam promover outras mulheres na empresa, é preciso que os homens aceitem promover uma mulher. Tive muita sorte de encontrar um chefe que confiou em mim e me ajudou a progredir quando eu era jovem.... Enquanto fui a única mulher na direção me consideravam como uma secretária, ajudando os homens 
em problemas de logística... Mas o "teto de vidro" é real: os homens têm sempre a possibilidade de progredir na carreira e as mulheres param num certo patamar”.

Note-se que esta engenheira procurou ascender de várias formas na organização, seja pedindo transferência para áreas operacionais , ou ainda se dispondo a trabalhar no exterior, já que seu marido poderia acompanhála, mas esses padrões muito avançados para a época não correspondiam à visão do banco sobre os lugares mais adequados para as mulheres, ou seja, as áreas de logística, de suporte, de pesquisas e estudos e o território nacional . Então, enquanto seus colegas homens ascenderam para posições de alta gerência, ela foi excluída desse seleto grupo ficando sem promoção durante mais de uma década. Além disso, como ela mesma conta, enquanto foi a única mulher na sua posição na empresa, atribuíam-lhe tarefas de logística, apoiando, como uma secretária de altíssimo nível, o grupo de colegas homens.

2.1. O importante papel sócio-profissional dos "clubinhos" masculinos

Antonieta, 47 anos, engenheira de produção brasileira também trabalha num grande banco privado no Brasil e lá ocupa uma posição , na suas palavras, "de poucos", comandando uma equipe de planejamento e controle com 20 homens; ela, contudo, se reconhece "numa posição abaixo da diretoria”. Da mesma maneira que Chantal, afirma haver diferença entre as carreiras dos homens e das mulheres no banco. Mas Antonieta vem refletindo muito sobre o que faz essa diferença e nos coloca seus pontos de vista: tanto do lade da organização ; como -do lado das mulheres há razões que conduziriam a uma diferença nas suas carreiras quando comparada às dos homens. Diferença que pode ser medida em termos de velocidade de ascensão e , também, em função de um posicionamento diferente frente ao trabalho. Antonieta constrói uma analogia com a época das cavernas, bastante criativa e interessante para resumir esse posicionamento diferente de homens e mulheres perante 0 trabalho: para o homem, o que importaria é delimitar seus territórios e cuidar que eles não sejam ameaçados e para a mulher, o trabalho seria como sua cria, que ela quer ver valorizada e para isso trabalha muito. 
Analogias à parte, em sua experiência como gerente na área bancária, na qual construiu sua carreira profissional, esta engenheira reconhece a existência dos "clubinhos" masculinos que defendem as melhores posições hierárquicas para seus membros e não têm muita "predisposição para ouvir as mulheres, falam mais alto nas reuniões, então $\mathrm{v}$. tem que brigar para falar". A não ser que elas se façam ouvir, como uma colega sua que "entrou com os dois pés na porta de quem tinha que tomar a decisão de promovêla, hoje ela é diretora”. Antonieta pretende um posto na diretoria do banco e para isso está disposta a brigar por ele de forma mais explícita, mais masculina. Como ela diz,

"acho que daqui para a frente a coisa tem que ser mais na linguagem masculina... senão, se $v$. continuar trabalhando e não disser nada, prá que ( eles vão) arcar com esse ônus ?"

Amália, engenheira de minas, 53 anos, também se refere à sua maneira ao mesmo "clubinho" de homens, a partir de sua convivência com eles na sua área de trabalho, "um mundo masculino". O "clubinho" enquanto espaço informal de trocas entre os engenheiros cobre também a importante função de fórum de discussão técnica, como detectou Mellström (1995) na pesquisa realizada em uma indústria automobilística sueca. Nos espaços de informalidade como os almoços, as pausas para café nos corredores do departamento de projetos, desenho e desenvolvimento daquela indústria muitas questões e problemas de trabalho que envolviam soluções técnicas e tecnológicas eram discutidas ao lado de assuntos não técnicos, esportes etc. Se uma engenheira é normalmente alijada da convivência nesses espaços masculinos, ela corre o risco de ser excluída da discussão técnica que acontece entre os seus pares. Amália explica porque é diferente ser mulher num grupo de homens, sobretudo se ela está em altos postos:

“Acho que em todos os lugares é sempre diferente ser mulher... o mundo masculino tem um conjunto de regras. Eu sinto mais nos primeiros contatos, depois, com o tempo, como sou muito brincalhona, falo bobagem, acabo deixando as pessoas mais à vontade. Mas num primeiro momento eles seguram a linguagem, não falam palavrão e como nos altos postos (a 
maioria) são homens, eles se permitem essas atividades... as mulheres quando estão em altos postos são seríssimas, elas não brincam, os homens brincam, falam dos hobbys, as mulheres estão sempre mais preocupadas nessa posição, que sempre é excepcional, ainda não está incorporada... então, não vou no mesmo banheiro, não torço para o mesmo time, faz diferença, não é a mesma coisa”.

Cláudia, engenheira civil e sindicalista de 48 anos, hoje no alto escalão de uma empresa da área de saneamento, revela um pouco mais sobre os mecanismos masculinos de cooptação que observou no seu percurso na empresa e avança, desvendando também o lado da mulheres. Segundo essa engenheira, em geral, a mulher prefere não se expor demais nas disputas por cargos, se preservando e, ao mesmo tempo se conformando com o fato de não ter altos cargos. Mas, na sua opinião é necessário que as mulheres lutem para chegar a esses cargos e usem todas as suas habilidades, com esse objetivo.

"Em alguns ambientes isso fica mais forte, p.ex., para pegar um cargo aqui hoje, v. tem que brigar muito.... as escolhas, é "naturalmente" uma ação entre amigos, puxam alguns colegas da turma, neguinho depois sai de noite e vai tomar seu chopinho.. constrói uma teia...é entre eles, um código meio masculino, acho que a mulher incomoda em algumas coisas. Principalmente neste meu mundo , da área da engenharia...., as mulheres são superprestativas, extremamente responsáveis, não deixam uma tarefa para trás, mas estão sempre disponíveis. Elas se conformam com algumas coisas, como não ter cargos, .....se tiverem que disputar abertamente, elas se recolhem um pouco... sem ter que se expor muito. Mas tem hora que a gente tem que se impor .......eu procuro sempre puxar as engenheiras ( para cargos de chefia), mas acho que elas são mais frágeis mesmo.....Agora, ...v. pode ser mulher e ajuntar um jeito mais combativo, senão ela fica sempre riscada de algumas posições. Informalmente, na maior parte 
das famílias, a mulher é quem manda, quem pilota. A questão é quando esse mundo formal vai se aproximar do informal... Acho que devíamos usar todas as nossas habilidades para pilotar processos e menos para servir processos"

2.2. A engenheira gerente e sua posição no grupo majoritariamente masculino.

Cláudia relembra comportamentos masculinos que a incomodaram na sua trajetória na empresa, como por exemplo, quando seu diretor lhe pediu _ e ela já era chefe de divisão_ "para recolher as xícaras de café” ou seus colegas pediam para "secretariar" a reunião, na qual ela era a única mulher. São indícios das concepções de gênero no mundo profissional, preconceitos profundamente arraigados, gerando comportamentos automáticos, ou como ela diz, que estão "no winchester" do homem. Nas suas palavras:

“... A gente tem os preconceitos de sempre, as mulheres loiras burras, as gostosas, as inteligentes feias, a gente tem que lutar. Mesmo aqui, no começo....hoje todo mundo já me conhece, é em mais fácil...O dia em que tomei posse na Associação dos Engenheiros da empresa (como presidente), estava todo mundo conversando, não tinha café, me pediram para passar um... era a única mulher. É ato falho mesmo. Como marido com computador, quando v. faz uma pergunta, ele começa com aquelas perguntas básicas: pôs na tomada? Apertou o on? ... como se v. tivesse um chip faltando porque é mulher."

Para Aurélia (engenheira civil e docente , 53 anos), contudo, esses atos falhos não seriam assim tão inocentes, mas uma forma de reafirmar a posição subordinada das mulheres no grupo , particularmente daquelas consideradas sérias concorrentes.

"Se tiver uma reunião de professores e tiver uma mulher, aquela vai ser escolhida para secretariar a reunião; agora, se for um cargo de comando, a mulher 'e esquecida, ela tem que falar "eu quero" e assim mesmo, às vezes, eles dizem 
"não dá”. Então eu percebi essas coisas, mas eles sempre arranjam um jeito de falar que a pessoa é incompetente, por trás... eles falam muito por trás”

Outra questão lembrada por Cláudia é a maior disponibilidade que os cargos de alto escalão exigem tanto dos homens como das mulheres. E no caso delas, a família e os filhos continuam sendo um obstáculo à ascensão. Cláudia acredita que é necessário fazer escolhas e estar consciente delas; no "mundo executivo", masculino por essência, estender o expediente até mais tarde ou viajar com certa freqüência são comportamentos esperados.

"Porque no fundo $v$. tem que fazer escolhas... o chefe fica até 9 horas, se eu tivesse que ir para casa, preparar jantar, cuidar de filho... é lógico que eu tenho minhas obrigações e eu procuro manter, não ser como eles, porque eu não quero ser um " homem inteligente”. Hoje me permito pôr um vaso, algumas coisas de que eu gosto na minha mesa... v. está mais madura, né? Poder ser sutil, ter algumas habilidades femininas, acho que v. promove mais conversa, acho que isso foi um dos atributos pelos quais o atual chefe me pegou, ser mais criativa, saber lidar com pessoas...Mas vejo o perfil das mulheres que estão em altos cargos atualmente; não têm filhos... as mais novas acho que conseguirão fazer as mesmas coisas sem ter que abdicar de tudo isso"

Cláudia e outras engenheiras entrevistadas tocam num ponto importante, qual seja, sua capacidade "relacional" ou a sensibilidade e a habilidade para lidar com as pessoas , estabelecer relacionamentos com os subordinados e também sua criatividade, como pontos que foram relevantes, na sua promoção aos postos de gerência e diretoria. Habilidades femininas desejáveis para gerir os conflitos humanos nas equipes, indicadas atualmente por alguns consultores empresariais como uma das vantagens da gerência feminina, face à masculina.

Marina, 44 anos, engenheira eletrônica, consultora autônoma, compartilha dessa opinião quando afirma que numa determinada época de 
sua trajetória profissional, decidiu que se chegasse a postos de comando, chegaria "sendo mulher", "expressando o que pensava, enquanto os homens calavam", em suma, diferenciando-se do padrão, "agindo como uma mulher numa profissão que é a engenharia”. Também Beatriz (engenheira química de 45 anos), gerente do departamento de pesquisas de produtos em multinacional do ramo químico, considera que além das capacidades técnicas e da competência recorrentemente comprovada, sua habilidade nos relacionamentos e sua capacidade de conciliação contaram pontos para que ela assumisse postos de gerência na empresa, nos últimos doze anos. Mas esses atributos "relacionais", que até então eram uma vantagem, transformaram-se em obstáculo à continuação da sua progressão hierárquica, à sua promoção a um posto na diretoria da empresa. Em outras, palavras, Beatriz passa a ser culpabilizada por conciliar "em excesso". Segundo seu relato:

"Senti (dificuldades na ascensão na empresa) sim. Eu acho que as mulheres de forma geral têm que provar muito mais, todo dia, que elas conseguem matar dez leões. Eu senti isso algumas vezes, não só comigo, mas algumas vezes as mulheres eram preteridas na oportunidade de ascender e colocavam um homem. ... não sei, a gente tem que provar mais, mostrar mais, ser mais completa para merecer aquela posição. ... Agora, o fato de ser mulher $e$ ter facilidades (por isso) aqui dentro, não são muitas. Acho que a mulher constrói mais relacionamentos, não é muito focada em hierarquia, é... mais da concordância. Isso é uma coisa que tem me prejudicado às vezes. Os homens acham que a gente deveria ser mais combativa, então às vezes eu ouço, "v. é muito da conciliação" e algumas vezes $v$. tem que ser mais brigona, assertiva. Talvez esse meu estilo, porque isso pode ser uma particularidade minha agregada ao fato de eu ser mulher, tenha me prejudicado. Talvez se fosse um homem mais conciliador não fôsse visto dessa maneira. Acho que isso tem me prejudicado, é uma coisa que me tem sido apontada como defeito, v. tem 
que ser mais assim ou assado... a gente é avaliada por homens, à luz do que é valor para os homens e não para as mulheres. ... acho que tem que ser criada uma nova mentalidade hoje nas empresas, tem muitas mulheres em cargos de chefia, executivas... essas mulheres têm outros valores. Então, acho que as organizações vão ter que se moldar, essas réguas foram aplicadas no passado, hoje em dia a régua é outra. A régua é outra e a gente continua medindo as pessoas com aquela mesma régua."

Beatriz toca num outro ponto crucial: a empresa é um espaço público e masculino, em contraposição ao espaço privado e feminino, e será sob essa ótica de valores que se darão as avaliações de desempenho, dos homens e das mulheres que lá trabalham. Reproduzem-se assim, as imagens e as concepções sociais de gênero em todos os níveis da hierarquia, atribuindo atividades profissionais diferenciadas a cada um deles segundo aquelas concepções. Se a mulheres estão em cada vez maior número nas empresas de um modo geral e nos cargos de comando, em especial, o que suporia algumas mudanças naqueles padrões de valores, essas mudanças, até o momento, parecem não ter ocorrido . Como bem diz Beatriz, "a régua é outra, e a gente continua medindo as pessoas com aquela (antiga régua)”.

\section{3. (Re)Definindo a gerência no feminino}

Mas haveria um modo feminino de gerenciar, dirigir pessoas, diferente daquele masculino? As entrevistadas revelam a ambigüidade da situação em suas avaliações. Beatriz acredita que é possível chegar a uma fórmula mais feminina, baseada num relacionamento mais próximo com os subordinados, conhecendo-os melhor, mais suave enfim. Ela acredita nessa fórmula e a contrapõe ao estilo "duro e masculino" de chefiar:

"Eu acho que facilidade por ser mulher é justamente por esse relacionamento mais fácil. As mulheres falam de outros assuntos que não do trabalho; comparo o ambiente aqui com o do meu marido, que é engenheiro metalurgista, eminentemente 
masculino. ... ele não sabe da família dos outros, mal e mal sabem quantos filhos têm e aqui a gente é uma família. Acho que as mulheres promovem mais essa abertura.... existe uma diretora, a mais nova delas , é extremamente agressiva... já causou alguns problemas, a área dela é a que tem maior rotatividade porque as pessoas não agüentam... na verdade eu acho que ela tem um estilo masculino, assumiu demais, talvez pelo fato de ser nova. Quando veio para o cargo de diretor, ela tinha 30 anos... acho que ela pensou que a maneira de se impor, porque todos os subordinados eram mais velhos que ela.. foi essa postura dura, muito masculina, aquele chefe que é um feitor, um capataz... se assustou com o poder, disse tenho que me impor, mas o respeito não se impõe, se conquista”.

Antonieta (47 anos, engenheira de produção, alta gerência de um banco comercial) também acredita que é possível tornar mais ameno o ambiente de trabalho, diminuindo a tensão e o estresse dos funcionários por meio de um bom relacionamento, mas concorda que as mulheres não “dulcificaram' a gestão das empresas pela impossibilidade de "quebrar alguns paradigmas no trabalho", ou em outras palavras, em função da própria organização do trabalho.

"No geral é muito tranqüilo (o relacionamento com os subordinados homens); acho que as mulheres não dulcificaram a gestão das empresas, realmente, é uma coisa difícil quebrar alguns paradigmas , o trabalho tem que ser feito, tem hora, v. tem prazos, não dá para amolecer, mas dá para conduzir isso de uma forma mais amena para as pessoas ...Consigo ser bem sucedida, as pessoas trabalham com um razoável conforto, (mesmo) com todo o estresse que tem a atividade. Mais humanamente"

Mirtes, engenheira química de 56 anos, hoje empresária do ramo têxtil, reafirma a importância de estabelecer um relacionamento mais 
humano do que os homens conseguiriam estabelecer com os subordinados, embora com limites e reafirma o desafio que significa assumir um posto de comando para uma mulher.

"Veja bem, ela (a engenheira) não tem que ser fria... A gente tem que ser mais humana do que os homens o são, mas $v$. tem que tomar cuidado para o outro lado não ultrapassar a área profissional porque às vezes tomam liberdades que não são necessárias. ...Hoje em dia, quando tem uma mulher num cargo importante, ela fala, não tem medo, é mais transparente, o homem é mais político. Esses (são) desafios para a gente..."

Os desafios que os postos de comando implicam são grandes e, para as mulheres ainda maiores, pois somente com a repetição da experiência elas podem encontrar um jeito próprio de comandar e sentir-se um pouco mais confortáveis nessas funções.Nesse sentido, a fala de Márcia, 50 anos, engenheira civil, atualmente chefe de um departamento em empresa de saneamento, é bastante esclarecedora.

“..(ser gerente)... v. lidar com pessoas com diferentes idades, culturas...... uma gerência depois da outra, venho tentando mudar... a forma de tratar as pessoas, a forma de conduzir a equipe, tentar administrar minha ansiedade sem descarregar na equipe... eu tenho uma coisa...não sei conviver com as pessoas sem mostrar que tenho uma relação de carinho, não consigo manter a distância por ser gerente, ou estou lidando com a pessoa (inteira) ou não estou..... isso nem sempre é bem visto. Tem pessoas que acham que v. tem que manter uma certa disciplina, uma certa distância... uma coisa mais impessoal... para mim é impossível. ... acho que é a minha forma (de gerenciar)"

Pelos depoimentos acima, pode-se concluir que os gerentes, diretores e chefes de ambos os sexos de uma forma geral, não podem escapar dos tempos e prazos e da cobrança de resultados, enfim das pressões que a 
organização do trabalho lhes impõe e que eles transferem aos seus subordinados. Nesse sentido, os estilos de gerência feminina e masculina não se diferenciariam, como também detectou Wajcman (1998) em um survey realizado na Inglaterra. Essa pesquisa se desenvolveu junto a gerentes de alto escalão em empresas multinacionais que operavam em setores tecnológicos avançados como petróleo, química e serviços de computador e que haviam implementado políticas de igualdade de gênero. Na interpretação daquela autora, o fato dos estilos de gerência não diferirem segundo o sexo do gerente se deve ao fato que esses estilos são moldados mais pelas organizações do que pelas pessoas. Porque as normas de desempenho e de conduta para posições de gerência de alto nível permanecem masculinas, as mulheres que quiseram ocupá-las, tiveram que adotá-las.

O que parece possível, atualmente, para algumas mulheres em altos postos de comando, como afirmaram as entrevistadas, é um pequeno espaço de manobra para a construção de um ambiente de trabalho mais descontraído e mais humano. Saber, como diz Marlaine, engenheira topógrafa francesa de 40 anos, "integrar a cabeça e o coração", "expondo seus sentimentos, mas levando os negócios de forma tão objetiva como os homens”. Essa questão tem sido recolocada em outros estudos, como o realizado por Bruschini (2004) com executivas brasileiras que trabalhavam em empresas de diferentes setores de atividade. Também entre uma parcela dessas mulheres emergiu uma compreensão da chefia feminina, segundo a qual não se desconsidera a racionalidade, a disciplina no trabalho e a cobrança de performance dos subordinados, mas se inclui a possibilidade de desenvolver um relacionamento mais caloroso e empático com a equipe, mais humanizado.

Então, para as mulheres gerentes e diretoras parece haver um duplo desafio: provar que são capazes de comandar equipes tão bem ou melhor que os homens e, também, dentro do estreita margem de manobra permitida pela organização do trabalho, encontrar um jeito próprio de gerenciar, que difira do proposto no modelo estabelecido. Em outras palavras, por se sentirem desconfortáveis como mulheres no desempenho daquelas funções tradicionalmente atribuídas aos homens, uma parte das gerentes e diretoras têm a oportunidade de, ao invés de negar a própria feminilidade, 
suprimindo-a, valorizá-la como marca da diferença. E, assim fazendo, elas estariam contribuindo para a reflexão coletiva sobre os modos de gerenciar em seus locais de trabalho (Laufer 1982).

2.4. Gerente engenheira, subordinados engenheiros: conflitos e desafios

Entre os desafios da chefia e da gerência, estão os conflitos que se estabelecem entre chefe e subordinados, potencializados no caso de uma engenheira que deve comandar um grupo de engenheiros homens. Marlaine, engenheira francesa da área de sistemas de informação, de 40 anos, relata os conflitos que se estabeleceram na sua primeira experiência de gerência. $\mathrm{O}$ dono da empresa convidou Marlaine, uma jovem que vinha da área de software para gerenciar uma equipe de cinco engenheiros, todos com mais de quinze anos de experiência e especializados em hardware. Resultado: um conflito que durou cinco anos e só teve um "final feliz" porque ela conseguiu encontrar um nicho de atuação que aliviava o grupo das questões "relacionais" com os clientes, dos problemas do pós-venda, não competindo com os subordinados na área técnica, conforme explica em seu relato:

"Anteriormente não havia uma instância de poder entre esses engenheiros e o dono da empresa. Foi o conflito total. Durante 5 anos eles resistiram à minha presença e aos poucos eu fui adquirindo força para reagir. $O$ chefe me defendia , pois sabia que de alguma forma eu teria com o que contribuir para a empresa. E eu me dizia sempre que como mulher e engenheira tinha uma contribuição a dar. Os engenheiros me viam como competidora, querendo tomar o poder, e a saída que encontrei foi me aliar aos clientes. Fazia, então, um tampão entre o cliente e a equipe técnica, salvaguardando a equipe dos problemas do cliente. Quando eles perceberam que poderiam deixar comigo essa função, as coisas correram melhor. Eram serviços pós venda. Deixei a competência técnica aos homens e me desenvolvi como consultora do cliente, sua advogada perante a empresa, 
acompanhando-o em congressos, feiras etc. Acho que tive sucesso nessa estratégia pois assumi o serviço de atendimento aos clientes em vários países”

Situação parecida com aquela relatada por Luzimar, 52 anos, engenheira eletrônica brasileira, residente na França, onde trabalha em uma montadora de veículos francesa, ao assumir um cargo de chefe do serviço de engenharia, bastante cobiçado pelos colegas engenheiros, os quais passaram a ser seus subordinados:

"Assumi um cargo de chefe do serviço de engenharia, um cargo muito valorizado e conceituado. Eu era adjunta de uma diretora. Foi a primeira vez que tive que lidar com conflitos ligados ao cargo de gerência de grandes equipes (100 pessoas). Os conflitos vinham da parte de outros colegas que queriam o cargo e se consideravam melhor posicionados para assumi-lo. Era para ficar 6 anos no cargo, mas depois de 2 houve uma reestruturação total do serviço de engenharia, que desapareceu”.

Ciúme da boa performance, da competência técnica, competição pelo cargo ocupado, não aceitação da gerência feminina por parte dos colegas homens, todos esses ingredientes reaparecem nas experiências de Marina, engenheira eletrônica de 44 anos, hoje consultora autônoma, trabalhando para várias empresas nas quais, invariavelmente "trabalha muito", empresas que a chamam para "resolver" um problema técnico ou gerencial. Abaixo, apresentamos trechos de seu depoimento.

"em 1996, na $1^{a}$ experiência como gerente, numa empresa de multimídia, eram só homens, uns 4, depois chegou a 12 ....um pessoal da matemática, preguiçosos, acomodados, medrosos. ... fiquei até 1998. Saí porque estava trabalhando muito, mas teve uma época legal, eu era apresentada como diretora de engenharia...Mas depois acho que criou um ciúmes entre eu e o Ângelo, então tinha uma visão Marina e uma visão Ângelo (de trabalhar). Ângelo não era engenheiro, Marina era e eu estava organizando muita coisa... tinha um 
ciúmes .. o Ângelo se aliou com um menino engenheiro que queria subir muito rápido e deu corda para ele. Mas esse menino era um cara que queria muito ascender mas não tinha força suficiente....(numa outra vez) me convidaram para ser gerente como prestadora de serviços, dando notas fiscais; fiquei 3 meses porque a dona me disse que eu ia ser diretora geral e isso não aconteceu. Lá entrei num projeto para gerenciar, dar uma organizada e para isso tive que comprar umas brigas e tinha um homem lá que queria o meu cargo... armaram em grupo de homens para me derrubar e a dona me mandou embora. Achei ótimo”.

\section{CONSIDERAÇÕES FINAIS}

Dentre todas as barreiras encontradas pelas engenheiras no exercício da sua profissão, talvez uma das maiores tenha sido assumir postos de comando. Essa dificuldade que atinge a maioria das mulheres, parece se potencializar no caso das engenheiras entrevistadas. Se a mulher ainda é a exceção na engenharia, daí decorre que a regra é encontrar equipes masculinas de profissionais.

Chefiar essas equipes, segundo os relatos analisados neste artigo, apresentou múltiplos desafios para algumas engenheiras, que, não raro, tiveram que ser suficientemente criativas e hábeis para lidar com situações de conflito explícito com os engenheiros subordinados.

$\mathrm{O}$ primeiro desafio diz respeito às possibilidades de as engenheiras chegarem aos cargos de comando, que são menores do que as dos seus colegas. Duas ordens de fatores parecem contribuir para a persistência dessa barreira ascensional. De um lado, parece se colocar o importante papel do grupo masculino de profissionais (o "clubinho"), mais numeroso e mais antigo na engenharia, o qual funcionaria como repositório de futuros gerentes e diretores das empresas, baseando-se em relações de confiança e solidariedade construídas no interior do grupo de homens, muitas vezes desde a escola, mas também no trabalho e, principalmente, fora dele, em encontros informais. Perante a inexistência de clubinhos no feminino, a ascensão das engenheiras tenderia a ser um processo de cooptação que depende de um 
chefe- geralmente um homem- que acredite e confie nelas, a ponto de lhes dar essa chance. Por outro lado, as mulheres apresentariam algumas resistências para assumir tais postos, seja porque não têm a disponibilidade de tempo e dedicação exigidas pelos cargos e pelas empresas, em razão da presença de família e de filhos, seja porque preferem se preservar a enfrentar a acirrada competição com os homens por esses cargos.

Um outro desafio residiria na necessidade da prova permanente da competência profissional, como maneira feminina de se auto afirmar perante o grupo de homens, sejam eles colegas, subordinados ou superiores, em ambiente profissionais majoritariamente masculinos, como a engenharia. Trata-se, portanto, de um diferencial de gênero, uma vez que a prova constante de capacidade não é exigida dos homens. Ainda, expostas a confrontos muitas vezes abertos com seus subordinados, as gerentes engenheiras ou diretoras tiveram que encontrar uma "brecha" para continuar no posto, de tal maneira que a convivência com os subordinados fosse possível. Em alguns casos, essa brecha significou abrir mão do exercício das atividades técnicas da engenharia em favor dos homens. Via de regra, essa acomodação se deu quando a gerente passou a se dedicar a atividades consideradas de cunho mais relacional, vistas como adequadas a uma engenheira.Deixando, portanto, a parte do trabalho considerada mais nobre- que envolve conhecimento e expertise técnica- para os homens.

$\mathrm{O}$ fato é que o comando feminino de maneira geral e, na área tecnológica em especial, é fato bastante recente nas organizações. Até o momento, ele requer, de um lado, a aceitação dos padrões masculinos de carreira esperados pelas empresas, por parte das mulheres que desejem desempenhá-lo e , de outro, a aceitação e a legitimação da autoridade feminina, por parte dos homens.. Após o primeiro impacto nesses postos, porém, as entrevistadas admitem que, se não é possível deixar de cobrar dos subordinados resultados e cumprimento de prazos, limites impostos pela própria organização do trabalho, a cujas exigências gerentes de ambos os sexos devem se submeter- é possível tornar o ambiente de trabalho mais agradável e amigável. E este tem sido apontado como um ponto a favor das mulheres, um diferencial de gênero na forma de gerenciar pessoas. 


\section{REFERÊNCIAS}

BEAUD, Stéphane; WEBER, Florence. Guide de l'enquête de terrain. Produire et analiser les données ethnographiques. Paris: La Découverte, Paris, 2003 (Coll. Repères).

BRUSCHINI, Maria Cristina Aranha; PUPPIN, Andréa Brandão. Trabalho das mulheres executivas no Brasil no final do século XX. Cadernos de Pesquisa. Campinas, no. 121, v.34, jan/abr 2004. p. 105-138.

FAULKNER, W. Belonging and becoming: Gendered processes in engineering', in Jacqueline Archibald, Judy Emms, Frances Brundy, Eva Turner (eds) The Gender Politics of ICT, Middlesex: Middlesex University Press, 15-26, 2005.

FORTINO, Sabine. La Mixité au travail. Paris: La Dispute, 2002 (Coll. Le genre du monde).

LAUFER, Jacqueline Huppert. La feminité neutralisée? Les femmes cadres dans l'entreprise. Paris: Flammarion, 1982.

LAUFER, Jacqueline; FOUQUET, Anne. Effet de plafonnement de carrière des femmes cadres et accès des femmes à la décision dans la sphère économique. Relatório final de pesquisa realizada sob a Convention d"etude avec le Service des Droits des Femmes, Ministère du Travail et des Affaires Sociales, Paris, novembro 1997.

MARRY, Cathérine. L'excellence scolaire des filles: une révolution respectueuse? Le cas des diplômées des grandes écoles scientifiques d'ingénieurs. Notes pour l'habilitation à diriger les recherches en sociologie, Université de Versailles - Saint-Quentin, avril 2002 (mimeo).

SILVA TELLES, Pedro Carlos. História da engenharia no Brasil- séculos XVI a XIX. Rio de Janeiro: Livros Técnicos e Científicos, volume 1, 1984. 
TERRA DA SILVA, Márcia. A engenheira, um estudo da divisão sexual do trabalho. Dissertação de Mestrado, Escola de Administração de Empresas de São Paulo-EAESP/Fundação Getúlio Vargas, São Paulo, 1992.

WAJCMAN, Judy. Feminism confronts technology. $2^{\text {a }}$ ed.. Pennsylvania: The Pennsylvania State University Press, 1996.

. Managing like a man; women and men in corporate management. Pennsylvania: The Pennsylvania State University Press, 1998. 